\title{
Process Intensification via Continuous and Simultaneous Isolation of Antioxidants: An Upcycling Approach for Olive Leaf Waste
}

\section{Final version: https://doi.org/10.1021/acssuschemeng.9b04245}

\author{
Virag $\operatorname{Voros}^{\dagger}$, Enrico Drioli ${ }^{\ddagger}$, Claudio P. Fonte ${ }^{\dagger, *}$, Gyorgy Szekely ${ }^{\dagger, \S, *}$
}

${ }^{\dagger}$ School of Chemical Engineering \& Analytical Science, The University of Manchester, The Mill, Sackville Street, Manchester, M13 9PL, United Kingdom

$\$$ Institute on Membrane Technology (ITM-CNR), Via P. Bucci 17/C, 1-87030 Rende, Cosenza, Italy

$\S$ Advanced Membranes and Porous Materials Center, Physical Science and Engineering Division (PSE), King Abdullah University of Science and Technology (KAUST), Thuwal 23955-6900, Saudi Arabia

* Corresponding authors:

claudio.fonte@manchester.ac.uk; +441613068869

gyorgy.szekely@kaust.edu.sa, gyorgy.szekely@manchester.ac.uk; +966128082769 www.szekelygroup.com

Keywords: hybrid processes; solid phase extraction; solvent recovery; process intensification; temperature swing adsorption; waste upcycling 


\begin{abstract}
Isolation of individual pharmaceutical-grade bioactive compounds from complex plant extracts is still a sustainability challenge. Process intensification improves manufacturing design to achieve significant benefits in process efficiency and operation, product quality, and waste management. A process optimization and intensification methodology for the simultaneous isolation of biophenols from agricultural waste using imprinted materials and nanofiltration membranes is reported herein. First, temperature-swing molecular imprinting technology was used to selectively extract individual biophenols from olive leaf extracts. Second, solvent-resistant nanofiltration was used to in line concentrate the product and waste streams as well as recover the solvent. The predictive mathematical models for the adsorption dynamics and the membrane separation resulted in a significant reduction in the carbon footprint, $E$ factor and economic sustainability. The process was designed for easy operation with multi-way valves to aid safety and reduce operating costs. The presented process intensification methodology can be generally exploited for waste upcycling through sustainable isolation of multiple high-value products from complex mixtures.
\end{abstract}

\title{
Introduction
}

Sustainable manufacturing of fine chemicals is one of the main goals of the 21 st century. The agricultural and industrial sectors are responsible for $57 \%$ of the greenhouse gas emissions contributing to climate change. ${ }^{1}$ There are aspirations to enable scientists and engineers to move towards more sustainable design and development of chemical processes used in the manufacture of pharmaceutical ingredients., ${ }^{2,3,4}$ Pharmaceutical, personal care, food and nutritional industries extract natural compounds from a range of plants and animals. In particular, there is an increasing interest in developing processes for the extraction of biophenols with diverse examples such as column chromatography, ${ }^{5}$ centrifugal partition chromatography, ${ }^{6}$ superheated liquid extraction, ${ }^{7}$ pressure drop texturing, ${ }^{8}$ reduced-pressure boiling extraction, ${ }^{9}$ ultrasound- and microwave-assisted extraction, ${ }^{10,11}$ and membrane processes. $^{12}$

Conventional downstream separation processes are often unsustainable due to their high share of total manufacturing costs and industrial energy usage. ${ }^{13}$ Through innovative approaches, process intensification aims to reduce the environmental burden and operating expenditures, while increase process efficacy, product quality, and reusability. ${ }^{14}$ Continuous processes ${ }^{15,16}$ and membrane-based separations ${ }^{17}$ can significantly improve the sustainability 
and economics of chemical manufacturing. ${ }^{18}$ The field of organic solvent nanofiltration (OSN) has significantly evolved in the past decade, and robust membranes are available for in line solvent recycling, which can drastically reduce solvent consumption. ${ }^{19,20,21}$ OSN has recently been proposed for the fractionation of lignin, ${ }^{22}$ flavonoids ${ }^{23}$ and polyphenol ${ }^{24}$ compounds. However, the obtained fractions contained a mixture or structurally similar compounds with similar molecular weight. Conventional olive leaf extractions result in a blend of polyphenols, and the isolation of individual compounds is yet to be developed. ${ }^{25,26}$ The reported methodologies use undesirable solvents (e.g. benzene, dichloromethane, diethyl ether) and their multicomponent mixtures, considerably basic or acidic conditions, and process steps at low $\left(0{ }^{\circ} \mathrm{C}\right)$ or high $\left(60{ }^{\circ} \mathrm{C}\right)$ temperature. ${ }^{5,27}$ Ethyl acetate was selected for this work because it is ranked as a green solvent in the GSK solvent selection guide. ${ }^{2,3}$ Note that the use of ethyl acetate in food and flavors depends on the country.

In our previous work, the synergistic coupling of imprinted materials with membrane-based separations was found to be an efficient process intensification tool for the isolation of highpurity oleuropein (OR) ${ }^{21}$ Concurrently, molecular imprinting has also been maturing into a robust and selective separation technology suitable for downstream processing. ${ }^{28,29}$ Biophenols occur in olive leaves, which are treated as agricultural waste after fruit harvest, although these compounds can be turned into high-value products. ${ }^{30}$ The beneficial properties of biophenols, in particular oleuropein, has been extensively studied. ${ }^{31}$ Besides its direct pharmacological use, oleuropein can be converted into various high-value compounds. ${ }^{32}$ Besides oleuropein other pharmaceutically important biophenols, particularly luteolin (LU) and pinoresinol (PN), can be found in olive leaves.

The present study demonstrates development and optimization of a continuous and simultaneous isolation process for three biophenols based on temperature-swing adsorption (Figure 1). The product and waste streams were concentrated, the solvent was in line recycled, and their effect on the $E$ factor, carbon footprint and economic sustainability of the process was investigated. The application of the hybrid process consisting of imprinting technology and nanofiltration can be extended to the isolation of other natural compounds from complex mixtures. 


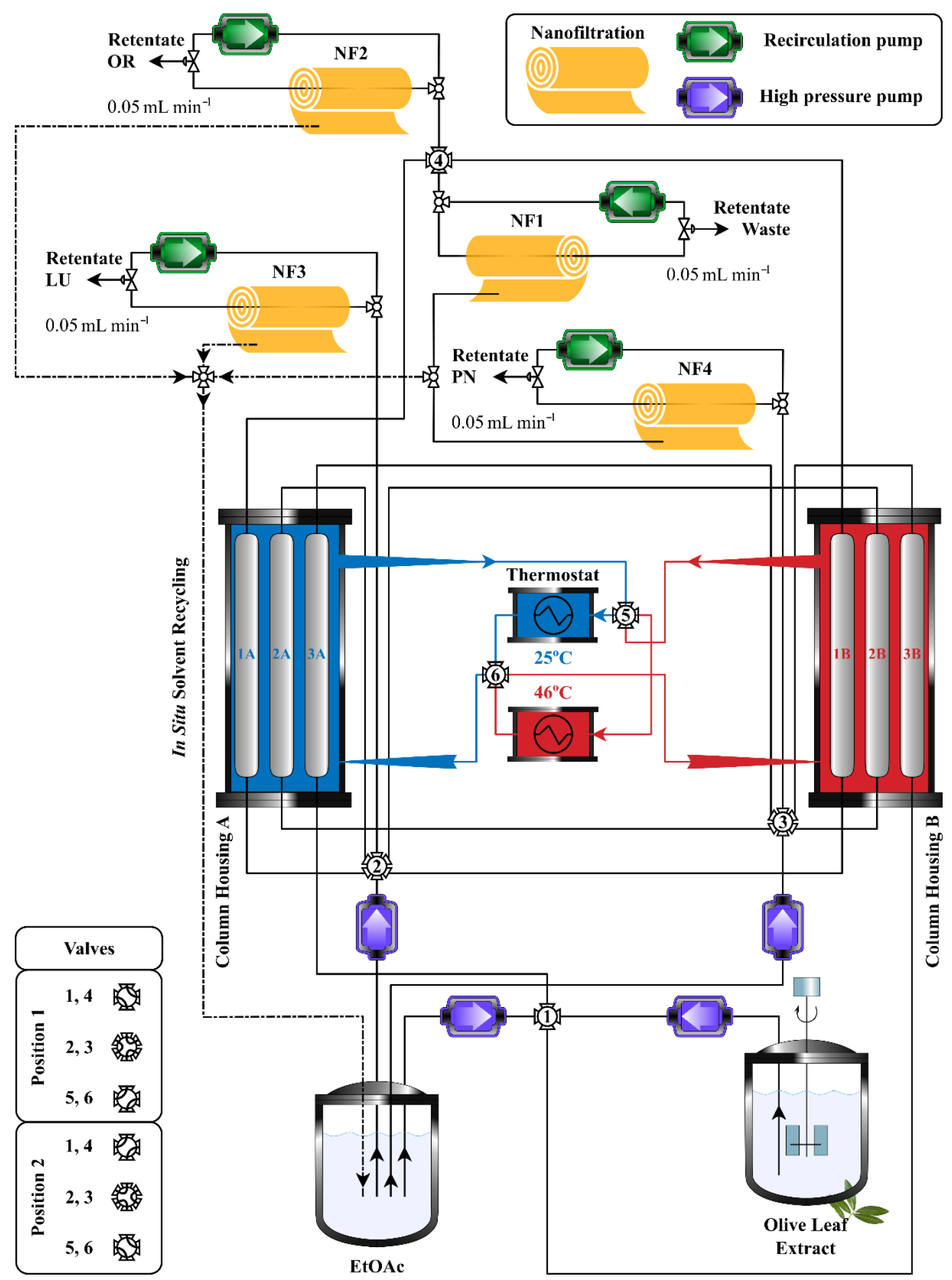

Figure 1. Schematic piping and instrumentation diagram for the continuous and simultaneous isolation and fractionation of oleuropein (OR), luteolin (LU) and pinoresinol (PN) from olive leaf extracts. The two sets of three columns are equipped with imprinted materials selective to OR (1), LU (2) and PN (3). Both the waste and biophenol streams are concentrated by the membrane units, while the ethyl acetate is in line recycled. 


\section{Materials and methods}

\section{General}

Reagents (reagent grade), solvents (analytical grade) and oleuropein, luteolin and pinoresinol standards were purchased from Sigma-Aldrich. The porogen acetonitrile was dried over $4 \AA$ molecular sieve. Millipore Type II water was employed for the membrane preparation. ${ }^{1} \mathrm{H}$ and ${ }^{13} \mathrm{C}$ NMR spectra were recorded on a Bruker AV-400 spectrometer. A VWR-Hitachi Chromaster DAD-HPLC equipment was employed for the analysis of the target compounds. ACE $5 \mu \mathrm{m}, 100 \AA$, C18 column with $150 \times 4.6 \mathrm{~mm}$ dimensions was used for the chromatographic separation, and the flow rate of the eluent was set at $1 \mathrm{~mL} \mathrm{~min}^{-1}{ }^{21}$ The volume of injection was $15 \mu \mathrm{L}$. Acetonitrile and Millipore Type I water containing $0.1 \%$ trifluoroacetic acid were used as eluents in channel A and B, respectively. The gradient was linear from 10 to $90 \% \mathrm{~A}$ in $60 \mathrm{~min}$, followed by $90 \%$ A hold for another $5 \mathrm{~min}$. At the end of the method a re-equilibration period was set for $15 \mathrm{~min}$. The temperature of the column housing was set at $25^{\circ} \mathrm{C}$. Mass spectrometry measurements were performed using a triple quadrupole mass spectrometer with positive electrospray ionisation source coupled to an Agilent 1100 HPLC equipment.

\section{Imprinted materials}

The fabrication of the imprinted materials was performed according to our previous procedure. $^{21} 2 \mathrm{mmol}$ of 1-(4-vinylphenyl)-3-(3,5-bis(trifluoromethyl)phenyl)urea, $1 \mathrm{mmol}$ styrene functional monomers, $1 \mathrm{mmol}$ biophenol as template, $15 \mathrm{mmol}$ ethylene glycol dimethacrylate crosslinker, $0.1 \mathrm{wt} \%$ recrystallized 2,2'-azobis(2-methylpropionitrile) radical initiator, $75 \mathrm{mg}$ perfluoro polymeric surfactant emulsifier, $60 \mathrm{~mL}$ perfluoro methylcyclohexane dispersing phase, and $15 \mathrm{~mL}$ solvent (porogen: acetonitrile) were mixed and vigorously stirred for $15 \mathrm{~min}$ under Nitrogen. The photopolymerization was performed over 6 hours by $365 \mathrm{~nm}$ irradiation with UV light under inert atmosphere. The obtained microbeads were washed with ethanol to remove any residual, unreacted components, and the template. The materials were dried in vacuo over a day at room temperature. Preparative chromatography columns (1), (2) and (3) with $250 \mathrm{~mm}$ length and $10 \mathrm{~mm}$ inner diameter were wet-loaded with approximately 8 grams of OR, LU and PN imprinted polymers, respectively. 


\section{Kinetic and adsorption isotherms}

$10 \mathrm{~mL}$ of standard solutions of $\mathrm{OR}, \mathrm{LU}$ and $\mathrm{PN}$ were prepared at $1 \mathrm{~g} \mathrm{~L}^{-1}$ concentration in ethyl acetate, which were loaded on 5, 15, 25, 50, 100, 150 and $200 \mathrm{mg}$ polymers. The vessel was sealed and agitated for $24 \mathrm{~h}$ at $25^{\circ} \mathrm{C}, 35^{\circ} \mathrm{C}$ and $45^{\circ} \mathrm{C}$, and $300 \mathrm{rpm}$ in an incubator shaker. For the quantification of the biophenols, the supernatants were analyzed by HPLC with 0.2 , $0.4,1,1.5,2,3,5,8,12$ and $24 \mathrm{~h}$ intervals.

\section{Assessment of membrane separation}

Biophenols in ethyl acetate at $1 \mathrm{~g} \mathrm{~L}^{-1}$ concentration were filtered under 35-45 bar pressure employing a cross-flow nanofiltration rig equipped with $52 \mathrm{~cm}^{2}$ polymer membranes. Solventresistant, poybenzimidazole-based membranes were used (refer to Section 8 and 9 of the Supporting Information). The permeance value of the nanofiltration membranes was determined by dividing the solvent flux with the applied pressure. On the other hand, the biophenol rejection ( $R$, Eq. 1$)$ were derived by measuring their permeate concentration $\left(C_{p e r m}\right)$, and calculating the ratio of the molecules retained by the membrane $\left(C_{r e t}\right)$. Three independent experiments were performed, and the average data and their standard deviations are reported in Figure S6 in the Supporting Information.

$$
R=1-\frac{C_{p e r m}}{C_{r e t}}
$$

Eq. 1

\section{Continuous separation}

The schematic of the piping and instrumentation diagram is shown is Figure 1. The feed concentrations for OR, LU and PN in the olive leaf extract were $0.966,1.042$ and $0.311 \mathrm{~g} \mathrm{~L}^{-1}$, respectively. The feed stream $\left(Q_{f}\right)$ is transferred at $2 \mathrm{~mL} \mathrm{~min}^{-1}$ flow rate from the storage vessel to Column Housing A set at $25^{\circ} \mathrm{C}$ for the adsorption of OR, LU and PN in Columns 1A, 2A and $3 \mathrm{~A}$, respectively. The adsorption utilizes Valves 1, 2 and 3 in position 1 allowing the extract to flow through Columns 3A, 2A and 1A, followed by the concentration of the waste stream leaving Column 1A diverted into the nanofiltration unit (NF1) through Valve 4 in position 1. The membrane area and the total volumetric flow rate ( $\alpha$, Eq. 2) was $104 \mathrm{~cm}^{2}$ and $2.5 \%$ for all nanofiltration units. The solvent is recycled as the permeate stream at a flow rate of $1.95 \mathrm{~mL} \mathrm{~min}^{-1}$, while the retentate is collected as a concentrated waste stream at a flow rate of $0.05 \mathrm{~mL} \mathrm{~min}^{-1}\left(Q_{r e t}\right)$. 
$\alpha=\frac{Q_{r e t}}{Q_{f}}$

Eq. 2

Simultaneously, ethyl acetate solvent is transferred at $2 \mathrm{~mL} \mathrm{~min}^{-1}$ flow rate from a storage vessel to Column Housing B set at $46{ }^{\circ} \mathrm{C}$ for the desorption of OR, LU and PN from Columns 1B, $2 \mathrm{~B}$ and $3 \mathrm{~B}$, respectively. The adsorption utilizes Valves 1, 2 and 3 in position 1 allowing the desorbed and pure OR, LU and PN streams to be transferred into their individual nanofiltration units (NF2, NF3 and NF4, respectively) through Valve 4 in position 1 . The solvent is recycled as the permeate stream at a flow rate of $1.95 \mathrm{~mL} \mathrm{~min}^{-1}$, while the retentate is collected as a concentrated product stream at a flow rate of $0.05 \mathrm{~mL} \mathrm{~min}^{-1}$.

The temperature-swing adsorption is realized by switching Valves 5 and 6 of the thermostats to keep allow adsorption and desorption to take place in Colum Housing $\mathrm{A}$ and $\mathrm{B}$ at $25^{\circ} \mathrm{C}$ and $46{ }^{\circ} \mathrm{C}$, respectively. In valve position 1, Column Housings A and B are used for adsorption and desorption, respectively. In valve position 2, Column Housings B and A are used for adsorption and desorption, respectively.

\section{Results and discussion}

\section{Adsorption thermodynamics}

A numerical model of the adsorption process has been developed to simulate the separation of the three biophenols under different conditions. Thermodynamic data of adsorption required in the model has been obtained experimentally and can be found in Figure 2. Fitting expressions have been obtained from the experimental points to relate $q_{\text {eq }}$ vs. $C$ in equilibrium at different temperatures $\left(25^{\circ} \mathrm{C}, 35^{\circ} \mathrm{C}, 45^{\circ} \mathrm{C}\right)$. Further details on the adsorption isotherm analysis can be found in Section 4 of the Supporting Information. 

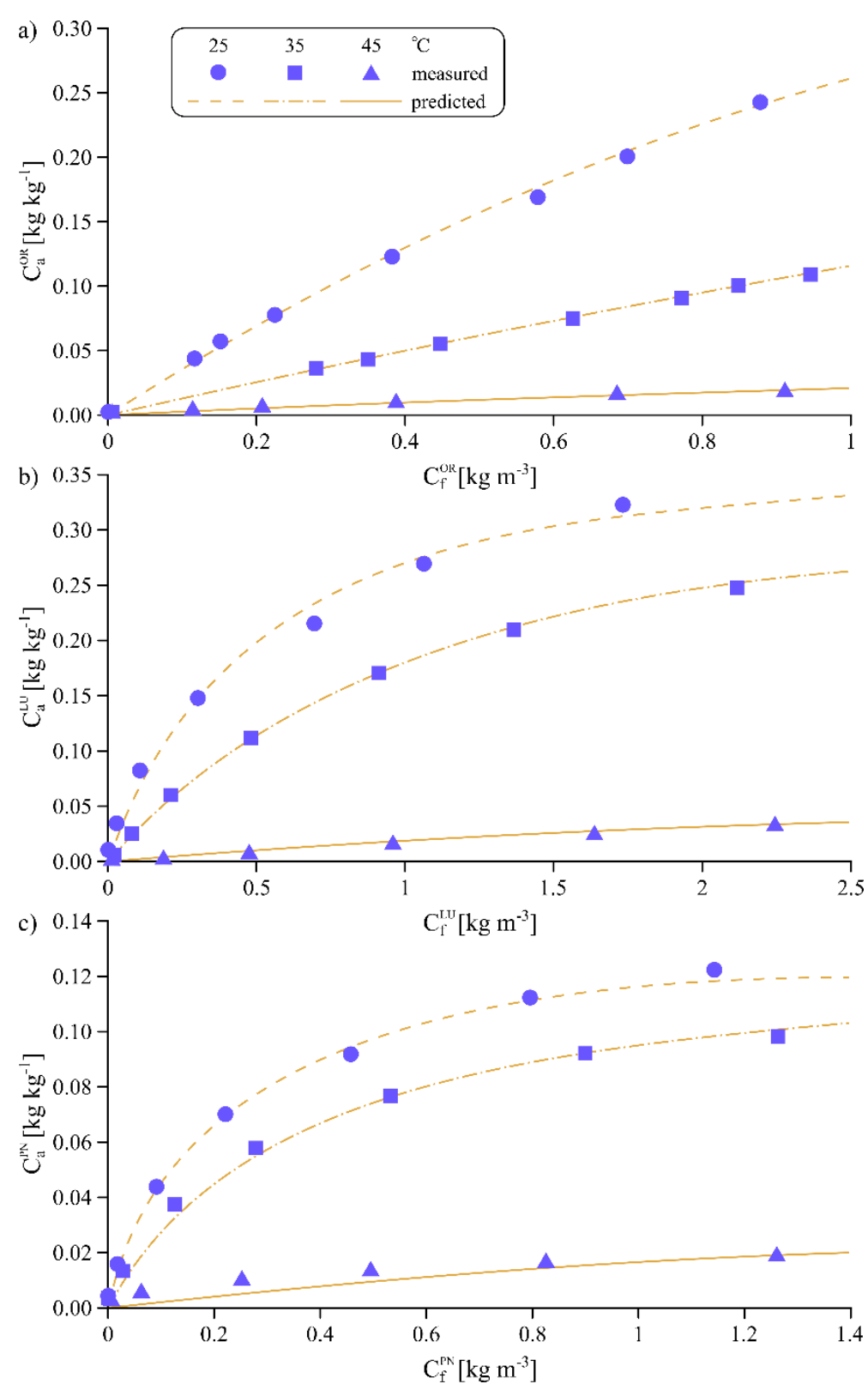

Figure 2. Adsorption isotherms at different temperatures for the different biophenols: a) OR, b) LU and c) PN, respectively. $C_{f}^{i}$ and $C_{a}^{i}$ are the free and adsorbed concentrations of compound $i$. The symbols indicate experimental data points, while the curves are predicted based on modelling presented on Section 4 of the Supporting Information.

In addition to the equilibrium thermodynamic data, the kinetics of adsorption have also been determined experimentally. This information has been used to estimate an effective intraparticular mass diffusivity required by the mathematical model of the columns. Figure 3 shows the experimental results obtained for the time evolution of the concentration of each biophenol in solution versus the amount absorbed and the corresponding fitted expressions. Values of $D_{\text {eff }}=1.07 \times 10^{-14} \mathrm{~m}^{2} \mathrm{~s}^{-1}\left(R^{2}=0.983\right), D_{\text {eff }}=1.13 \times 10^{-14} \mathrm{~m}^{2} \mathrm{~s}^{-1}\left(R^{2}=0.980\right), D_{\text {eff }}=0.40 \times 10^{-}$ 
${ }^{14} \mathrm{~m}^{2} \mathrm{~s}^{-1}\left(R^{2}=0.995\right)$ have been obtained from non-linear regression for oleuropein, luteolin and pinoresinol, respectively. Section 6 of the Supporting Information presents further details on the evaluation of the effective intra-particular diffusivity from the experiments.

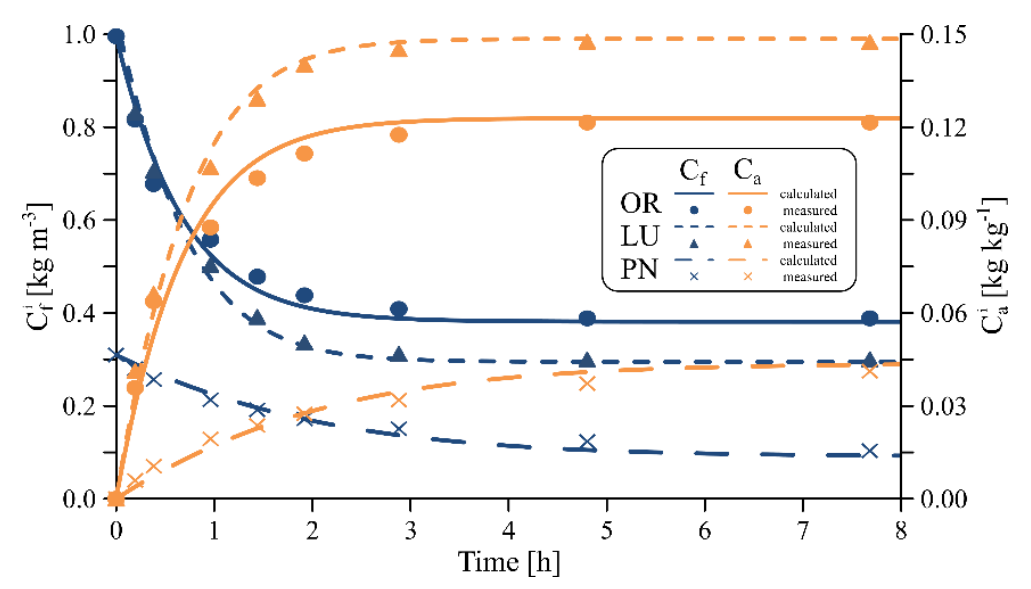

Figure 3. Kinetic data for the adsorbents for the estimation of the intra-particular effective diffusivity for OR, LU, and PN. $c_{f}^{i}$ and $c_{a}^{i}$ are the free and adsorbed concentrations of compound $i$.

\section{Column description}

The developed model of the adsorption separation process was used to simulate the system behaviour under different conditions, such as the effect of feed flow on the column outlet concentration $\left(C_{\mathrm{o}}(t)\right)$, the exploitation rate of the column capacity, and the loss of biophenols. Figure 4 shows the breakthrough curves for the different biophenols as a function of processed volume of olive leaf extract, which have been validated with experimental data for a flow rate of $2 \mathrm{~mL} \mathrm{~min}^{-1}$. Section 3 of the Supporting Information presents further details on the mathematical framework and assumptions. The main goal of the simulations was to define optimised injection times that minimise losses of biophenols but that maintain high column productivity rates (Figures 5 and 6.). 

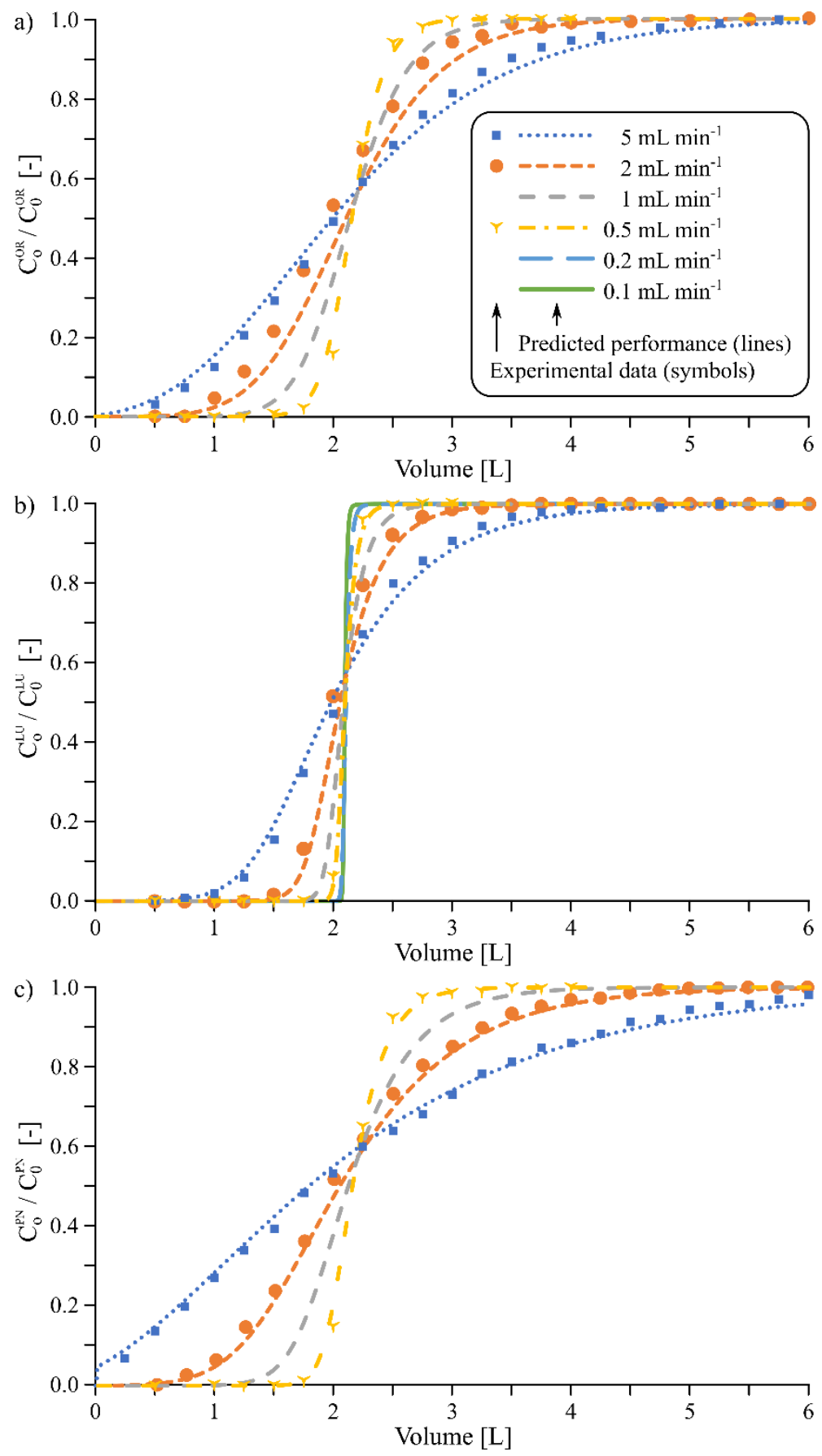

Figure 4. Optimization processing rates: breakthrough curves of a) OR, b) LU and c) PN $\left(C_{o}(t)\right)$ as a function of processed volume of olive leaf extract.

After validation, the mathematical model of the column was used to study the effect of the flow rate and the injection time on the process (refer to Section 7 in the Supporting Information). It has been observed that, as the inlet flow rate is increased, less residence time is given for biophenol molecules to adsorb until equilibrium is reached (Figure 4). At fixed flow rate values, an increase in the length of the injection time reduces the productivity with reducing the processed mass and leads to increasing biophenol waste. 

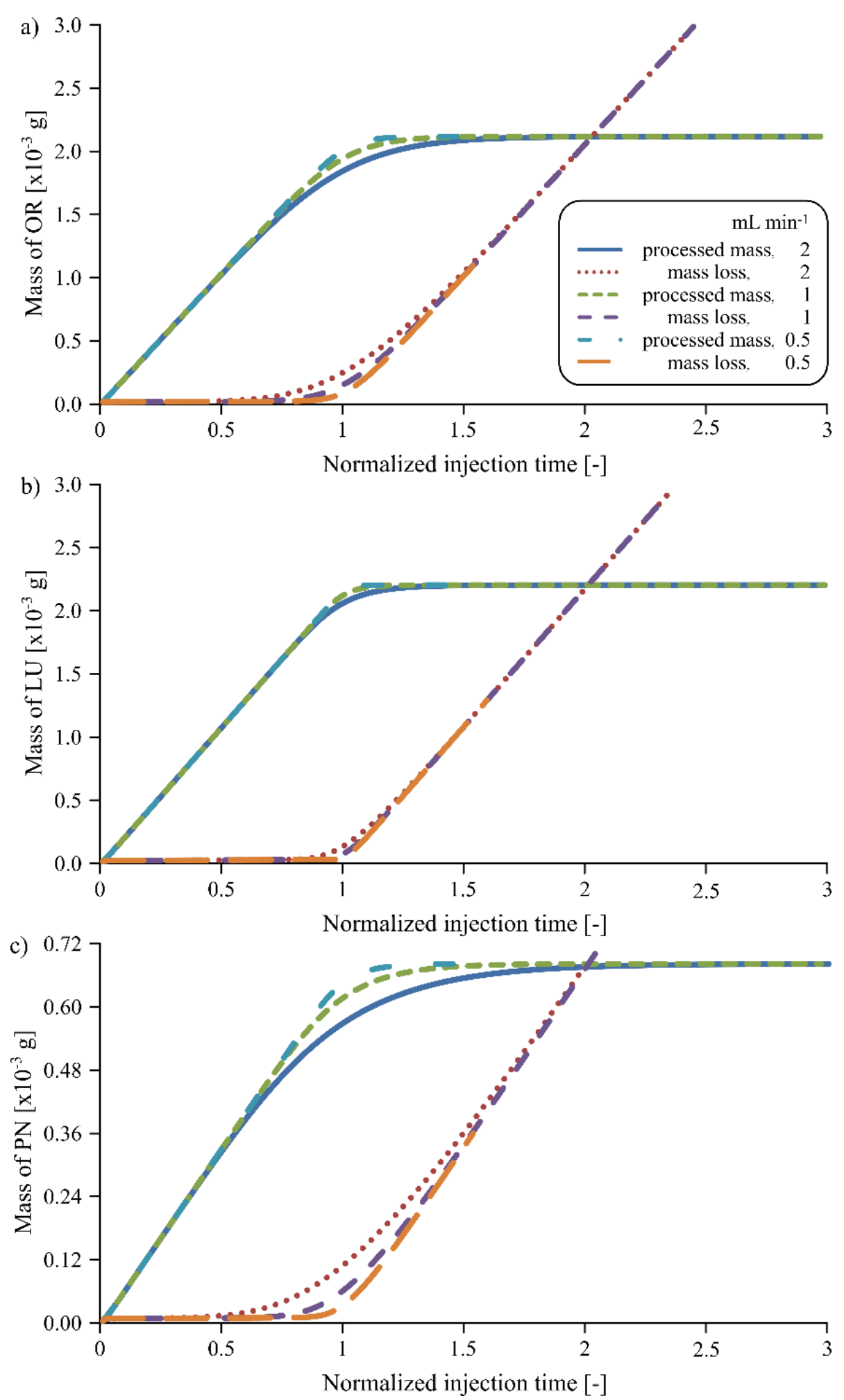

Figure 5. The effect of injection time on the normalized processed mass and the normalized mass loss of a) OR, b) LU, and c) PN at three different flow rates. 

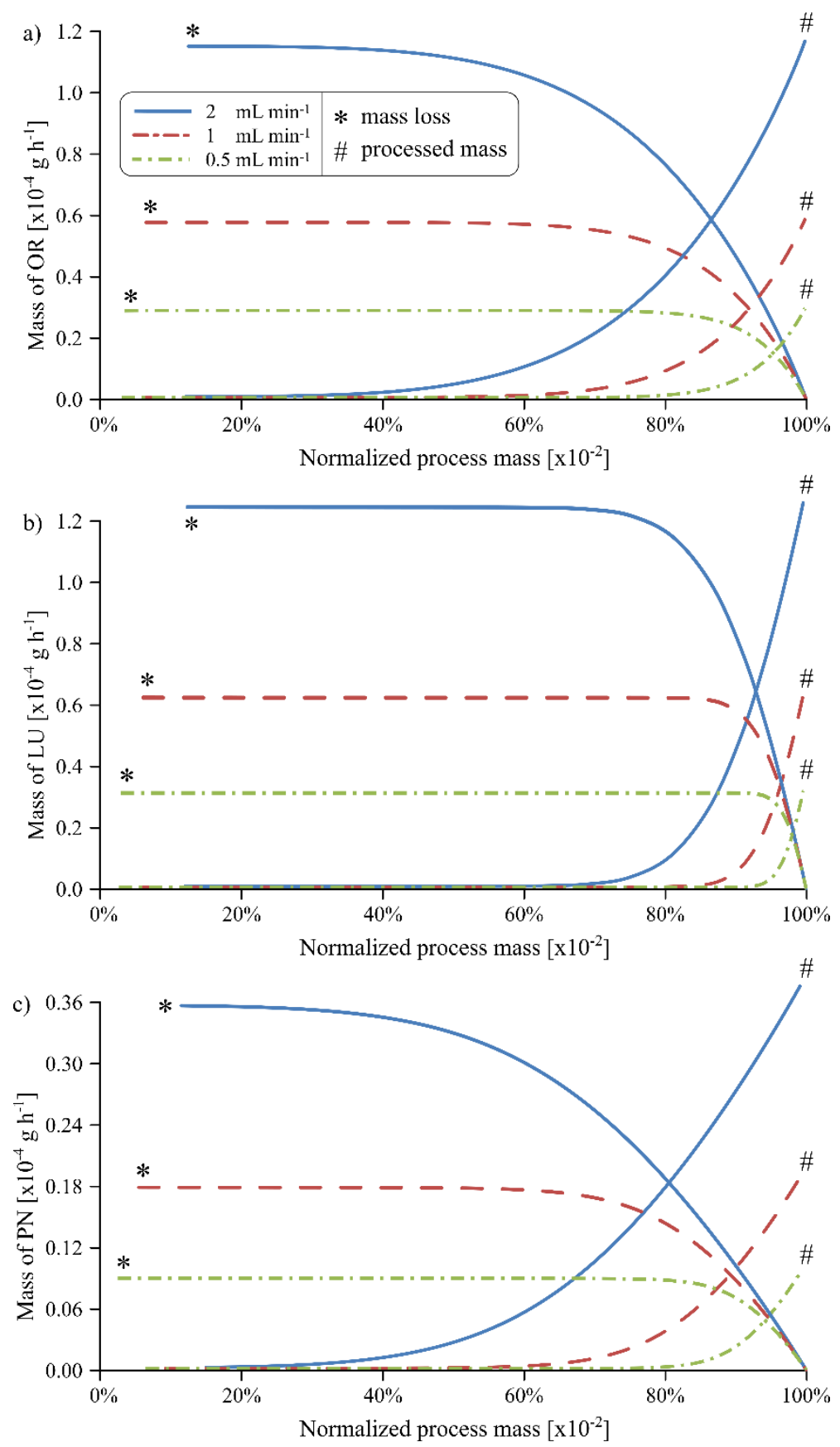

Figure 6. Mass loss $\left(^{*}\right)$ and processed mass (\#) as a function of normalized processed mass of a) $\mathrm{OR}, \mathrm{b}) \mathrm{LU}$, and c) PN.

The mathematical model was further used to determine desorption temperature that grants equal adsorption and desorption times. This was done in order to simplify the process control and operation and minimize energy consumption. The simulations have shown that $46{ }^{\circ} \mathrm{C}$ is the minimum temperature that ensures $99 \%$ recovery for all the biophenols in equal adsorption and desorption time (Figure 7a). This value was used for calculating the biophenol recoveries and the green metrics analysis. 

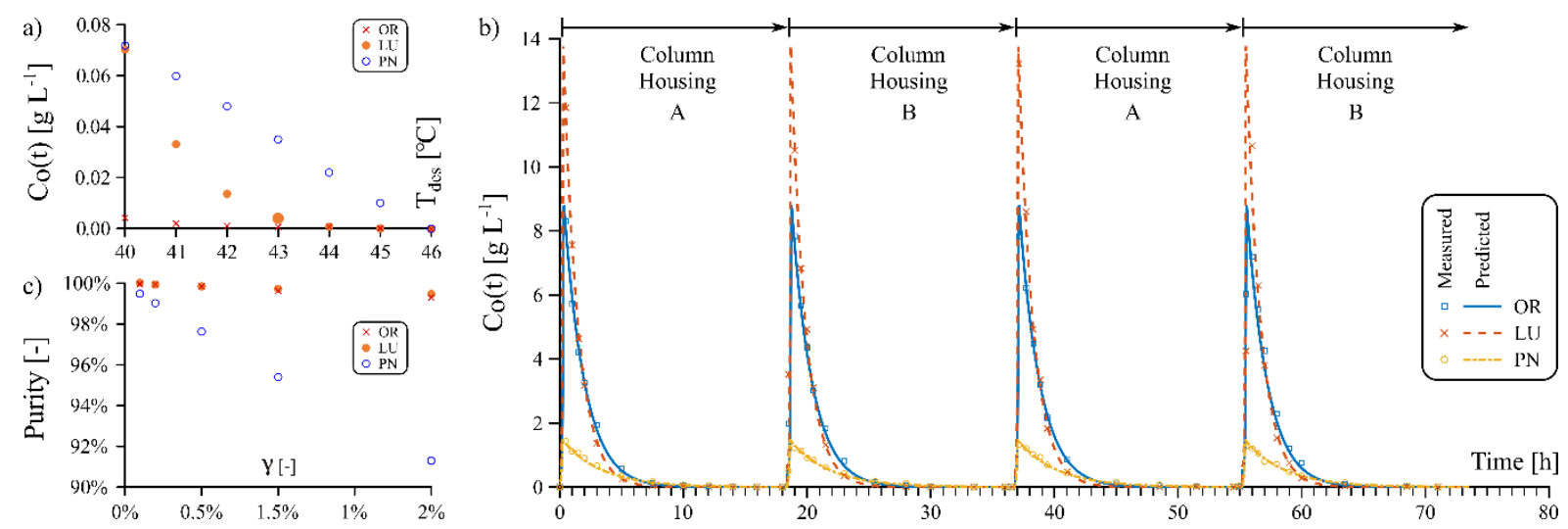

Figure 7. a) The effect of the desorption temperature on the concentration of the components at the outlet of the column $\left(C_{o}(t)\right)$ at $2 \mathrm{~mL} \mathrm{~min}^{-1}$ flow rate; b) Concentration profile for the continuous process at $46{ }^{\circ} \mathrm{C}$ desorption temperature and $2 \mathrm{~mL} \mathrm{~min}^{-1}$ flow rate: dynamics of biophenol concentrations at the outlet of the columns; c) The effect of column selectivity $(\gamma$, Eq. S13) on the purity in the outlet for the three components.

The selection of equal temperatures for the adsorption and desorption stages for all the biophenols offers easier control. Moreover, swapping between the columns can be done by simultaneously switching the six- and four-way valves after each cycle and allows the use of only two thermostats (see Figure 1). Minimizing the number of thermostats is crucial to achieve a sustainable operation. ${ }^{21}$ The outlet concentration profile for the hybrid process configuration with two sets of columns coupled with an in line solvent recycle step has been predicted with numerical calculations in a continuous mode up to 4 cycles (Figure 7b), $9.6 \mathrm{~g}, 13.3 \mathrm{~g}$ and $2.6 \mathrm{~g}$ product was isolated at a rate of $1.75,3.42$ and $0.12 \mathrm{~g}$ product per $\mathrm{kg}$ of adsorbent per hour for OR, LU and PN, respectively. Every second peak belongs to the same column housing due to alternating operation: desorption takes place $0-18 \mathrm{~h}$ and $18-36 \mathrm{~h}$ on column housing $\mathrm{B}$ and $\mathrm{A}$, respectively.

The good agreement between the measured and predicted concentration profile demonstrates that the system is stable over time. The desorption profiles are different for each biophenol. The highest peak was observed for LU as the desorption of this material is the fastest (see Figure $7 b$ ) and it has the highest adsorbed mass. This shows the different adsorption affinities of the individual biophenols for the imprinted materials. The sensitivity analysis revealed that even with a less selective ( $\gamma$, Eq. S13) column, still high purity (> 90\%) can be achieved (Figure 7c). A small change $(\gamma<2 \%)$ in selectivity has a negligible decrease in the purity of both OR (purity > 99.3\%) and LU (purity > 99.5\%). On the contrary, owing to the lower initial concentration and different adsorption isotherm properties (refer to Section 5 in 
the Supporting Information), the decrease in the purity of PN down to $91.3 \%$ is more pronounced.

\section{Membrane Separation}

The nanofiltration units coupled downstream of the adsorption, enabled the waste and product streams to be concentrated, and the solvent recycled to reduce the environmental impact by minimizing the amount of solvent waste and fresh solvent usage. ${ }^{33}$ Note that the recycled solvent is reused in the original process as it may contain process-related impurities, and therefore its use in other processes is not recommended without detailed impurity profiling. The concentrations at the retentate and permeate streams of the membrane are determined by two parameters: the rejection of the biophenols $(R, \mathrm{Eq} .1)$ and the fraction of the total volumetric flow ( $\alpha$, Eq. 2 ) as shown in Figure 8. The dynamics of the concentration of the components in the permeate $\left(C_{\text {perm }}\right)$ and retentate $\left(C_{\text {ret }}\right)$ can be described by Equations 3 and 4.

$\frac{d C_{r e t}}{d t}=\frac{Q_{f}}{V_{m}}\left(C_{o}(t)-\alpha C_{r e t}-(1-\alpha)(1-K) C_{r e t}\right)$ Eq. 3

$\frac{d C_{p e r m}}{d t}=\frac{Q_{f}}{V_{m}}\left((1-\alpha)(1-K) C_{r e t}-(1-\alpha) C_{\text {perm }}\right)$

where the absence of spatial gradients of concentration in the membrane cell volume $\left(V_{\mathrm{m}}\right)$ is assumed due to strong mixing induced in the recirculation loop, $C_{0}(t)$ is the concentration of the components at the outlet of the adsorption column, while $Q_{\mathrm{f}}$ and $Q_{\mathrm{ret}}$ are the feed and retentate volumetric flow rates. 


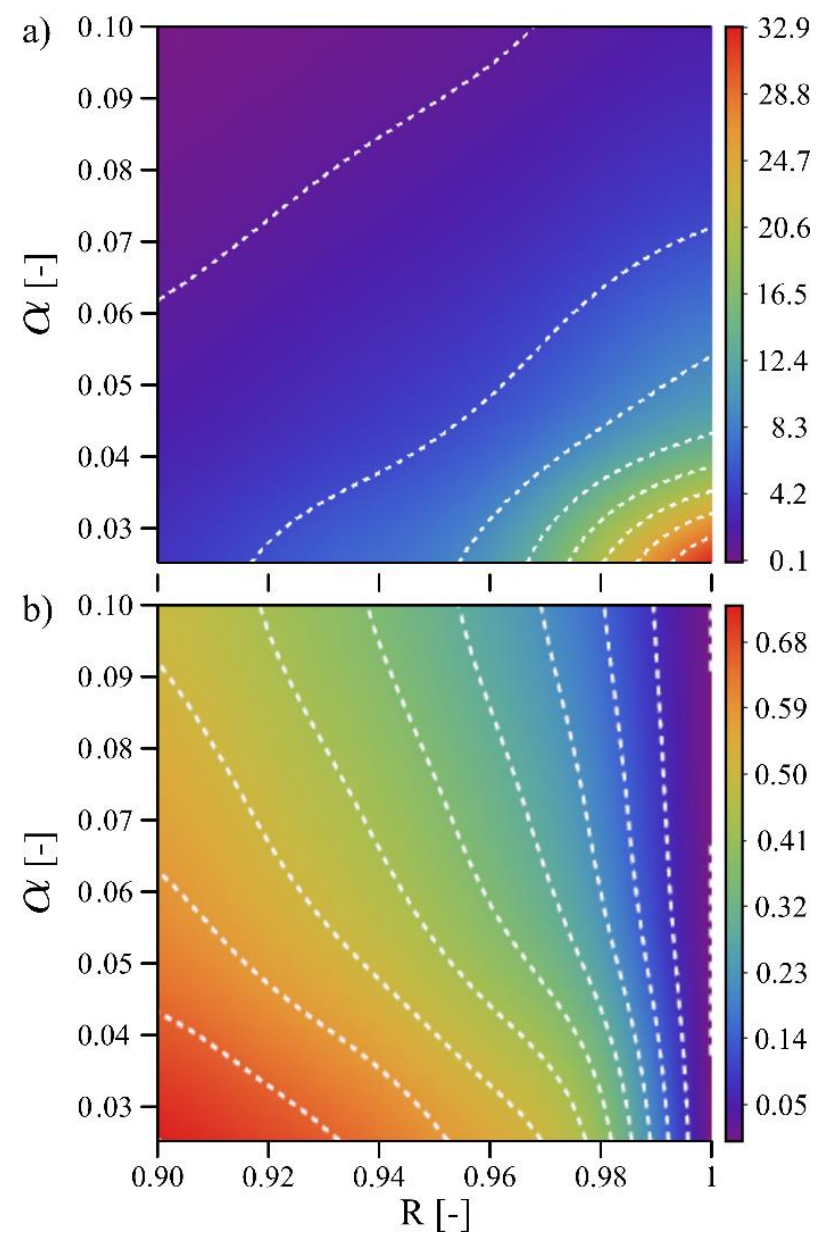

Figure 8. Concentration profile map of the continuous membrane process at steady state. The color bar represents the concentration of OR at the a) retentate and b) permeate streams in $\mathrm{g} \mathrm{L}^{-1}$ as a function of the fraction of the total volumetric flow rate $(\alpha)$ and the rejection of the membrane $(R)$. The contour lines represent $10 \%$ increment. Refer to Figure $\mathrm{S} 2$ in the Supporting Information for the concentration profile of the other biophenols.

The increase of rejection results in higher retentate and lower permeate concentrations, which favors product recovery via less product loss. On the contrary, the decrease of $\alpha$ favors product recovery, albeit the concentration in the permeate also increases. Figure 8 reveals that $\alpha$ has a more pronounced effect at lower rejections. Although the rejection is determined by the membrane, the $\alpha$ is a process parameter that can be easily adjusted to optimize the separation performance. For the best performance of the membrane separation, the rejection needs to be maximized and the $\alpha$ minimized. The resulting high concentrations should be monitored to avoid the precipitation of the biophenols. 
The concentration in the retentate gradually builds up during the continuous process (Figure 9, Table 1). The concentration has a reciprocal relation to the selected product mass loss. By shortening the duration of the cycles, the mass loss on the column increases, while the concentration of the retentate stream increases with lower amplitude (A, Eq. S23). Apart from $\alpha$, the allowed product mass loss can also be used to fine-tune the steady-state concentration in the membrane unit, and subsequently avoid precipitation of the biophenols.

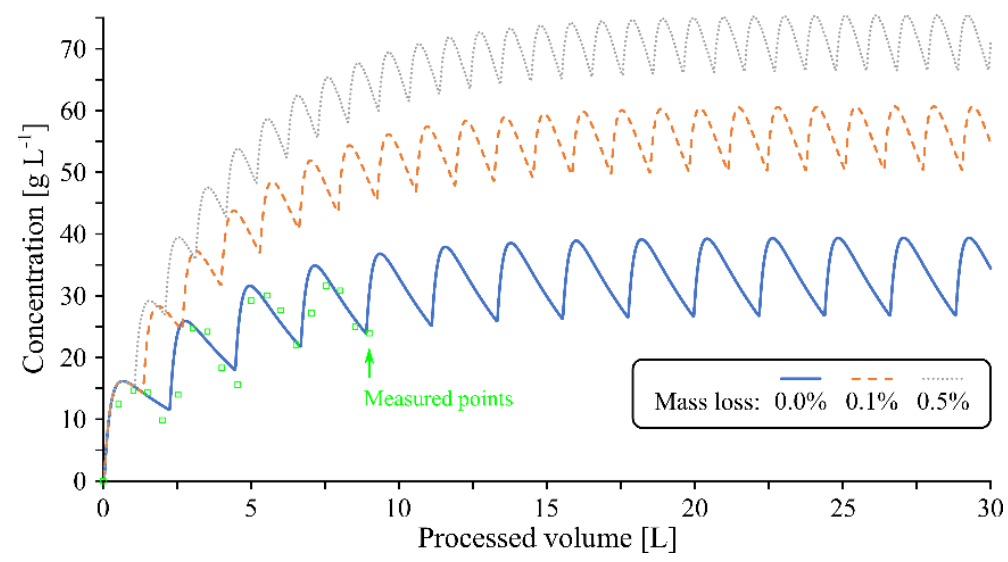

Figure 9. Retentate stream concentration profile of the continuous membrane process for OR as a function of processed volume at different mass loss values. Refer to Figure S3 in the Supporting Information for the concentration profile of the other biophenols.

Table 1. The effect of choice of product mass loss on the temperature-swing cycles and the membrane unit.

\begin{tabular}{cccccc}
\hline $\begin{array}{c}\text { Biophenol } \\
{[-]}\end{array}$ & $\begin{array}{c}\text { Mass loss } \\
{[\%]}\end{array}$ & $\begin{array}{c}{ }^{a} \text { Time per cycle } \\
{[\mathrm{h}]}\end{array}$ & $\begin{array}{c}{ }^{b} C_{s t} \\
{\left[\mathrm{~g} \mathrm{~L}^{-1}\right]}\end{array}$ & $\begin{array}{c}A \\
{[\%]}\end{array}$ & $\begin{array}{c}\text { \# of cycles to } \\
\text { reach steady-state } \\
{[-]}\end{array}$ \\
\hline \multirow{3}{*}{ OR } & ${ }^{\mathrm{a}} 0.0$ & 18.4 & 32.9 & 38 & 7 \\
& 0.1 & 11.0 & 55.3 & 19 & 11 \\
& 0.5 & 8.6 & 70.7 & 13 & 14 \\
\hline \multirow{3}{*}{ LU } & ${ }^{\mathrm{a}} 0.0$ & 18.4 & 11.8 & 123 & 2 \\
& 0.1 & 8.4 & 23.9 & 48 & 5 \\
& 0.5 & 6.5 & 30.9 & 33 & 6 \\
\hline \multirow{3}{*}{ PN } & ${ }^{\mathrm{a}} 0.0$ & 18.4 & 5.5 & 52 & 4 \\
& 0.1 & 17.5 & 5.8 & 48 & 4 \\
\hline
\end{tabular}

${ }^{a}$ The time per cycle equals to the required desorption and adsorption times. ${ }^{b}$ Refer to Eq. S25 and Figure S4 in the Supporting Information for the definition. 


\section{Process efficiency assessment}

The environmental sustainability of the simultaneous isolation process and the membraneassisted solvent recovery were demonstrated through the estimation of the $E$ factor and the ecological footprint defined in Eq. 5 and Eq. 6, respectively (Figure 10).

$E$ factor $=\frac{\mathrm{kg} \text { waste generated }}{\mathrm{kg} \text { isolated } \text { product }}$

Carbon footprint $=\frac{\text { equivalent } \mathrm{kg} \text { of } \mathrm{CO}_{2}}{\mathrm{~kg} \text { isolated } \text { product }}$

Eq. 6

The continuous, stand-alone processes for the isolation without solvent recovery of one of the biophenols generates $1834 \mathrm{~kg}, 1310 \mathrm{~kg}$ and $6878 \mathrm{~kg}$ of ethyl-acetate solvent waste for each isolated kilogram of OR, LU and PN, respectively. These values correspond to $3631 \mathrm{~kg}$, $2594 \mathrm{~kg}$ and $13617 \mathrm{~kg}$ of $\mathrm{CO}_{2}$ emission, respectively. The in line solvent recycle enables the industrial sector to reduce the environmental burden and expenditure on fresh solvent, storage of fresh and waste solvents, transportation and disposal. The hybrid process consisting of the continuous adsorption process of a single biophenol coupled with a membrane-based solvent recovery unit resulted in a $97.5 \%$ reduction in solvent consumption. Consequently, the $E$ factor of the hybrid process decreased to $67 \mathrm{~kg} \mathrm{~kg}^{-1}, 52 \mathrm{~kg} \mathrm{~kg}^{-1}$ and $236 \mathrm{~kg} \mathrm{~kg}^{-1}$, which corresponds to $96.4 \%, 96.1 \%$ and $96.6 \%$ decrease for $\mathrm{OR}$, LU and $\mathrm{PN}$, respectively. A more modest decrease of the carbon footprint to $3713 \mathrm{~kg} \mathrm{~kg}^{-1}, 2764 \mathrm{~kg} \mathrm{~kg}^{-1}$ and $14506 \mathrm{~kg} \mathrm{~kg}^{-1}$, which corresponds to $48.8 \%, 47.7 \%$ and $47.7 \%$ decrease was achieved, respectively. $E$ factor and carbon footprint of as low as $0.00125 \mathrm{~kg} \mathrm{~kg}^{-1}$ and $0.00248 \mathrm{~kg} \mathrm{~kg}^{-1}$ were achieved with in line solvent recycle, respectively. These elements contribute less than $0.01 \%$ to the total carbon footprint of the process. PN has considerably higher environmental burden than the other biophenols due to its lower concentration in the olive leaf extract: $0.311 \mathrm{~g} \mathrm{PN} \mathrm{L}^{-1}$ versus $0.966 \mathrm{~g} \mathrm{OR} \mathrm{L}^{-1}$ and $1.042 \mathrm{~g} \mathrm{LU} \mathrm{L}^{-1}$, which requires the process to run $274.8 \%$ and $424.4 \%$ longer to produce a kilogram of PN, respectively. 

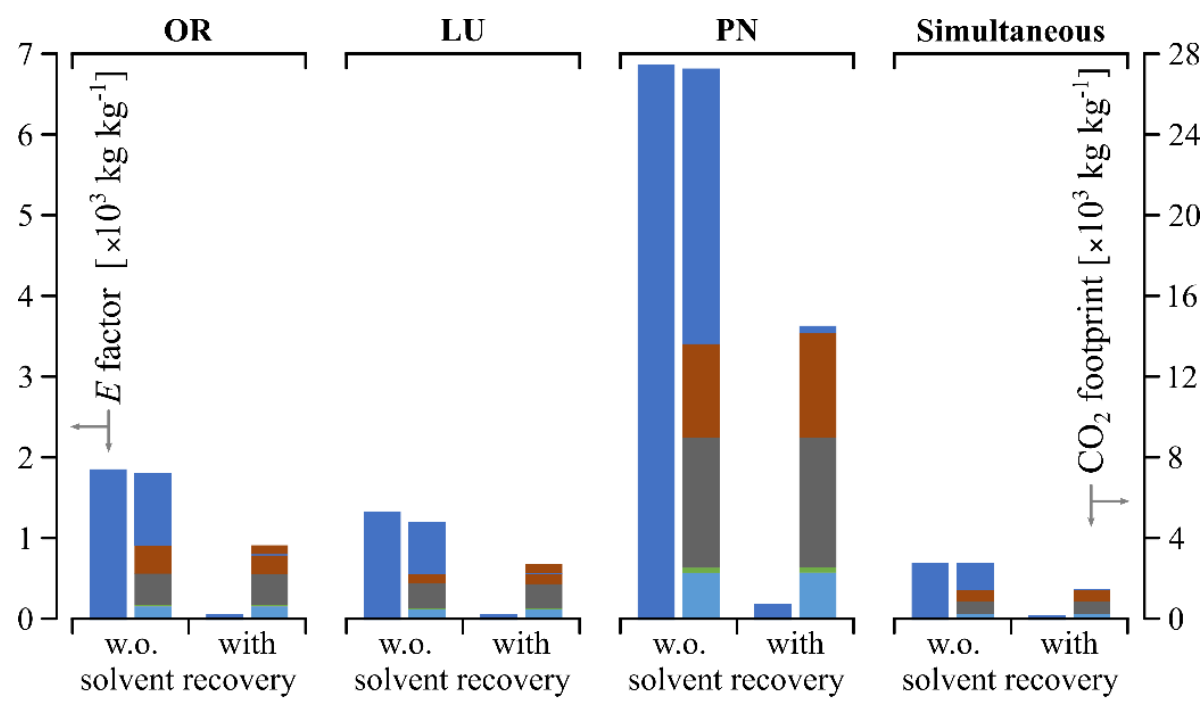

\begin{tabular}{|lrr|r|}
\hline $\begin{array}{l}\text { Membrane module } \\
\text { Olive leaf digestion }\end{array}$ & Recirculation pump & High pressure pump \\
$\begin{array}{l}\text { Stirrer } \\
\text { Adsorbent }\end{array}$ & Thermostat $25^{\circ} \mathrm{C}$ & Thermostat $46^{\circ} \mathrm{C}$ \\
\hline & Solvent & Dissolved matter \\
\hline
\end{tabular}

Figure 10. $E$ factor (left columns) and carbon footprint (right columns) estimations for single biophenol isolation without (left clusters) and with (right clusters) in line solvent recycle, and for the simultaneous isolation process. Refer to Table S7-18 in the Supporting Information for the breakdown of calculations.

An increasingly important aspect of implementing a technology is the cost of environmental burden over economic benefits. To evaluate these factors, we propose the use of economic sustainability (ES) parameters defined for waste and emitted $\mathrm{CO}_{2}$ as shown in Equations 7 and 8, respectively. Figure 11 shows the economic sustainability for stand-alone biophenol isolation and for the simultaneous biophenol isolation process based on the waste generated and emitted $\mathrm{CO}_{2}$ per million dollars in 2019.

$$
\begin{aligned}
& E S_{2019}^{W}=\frac{\mathrm{kg} \text { waste generated }}{\text { value of isolated product in } 2019} \\
& E S_{2019}^{\mathrm{CO}_{2}}=\frac{\mathrm{kg} \mathrm{CO}_{2} \text { emitted }}{\text { value of isolated product in } 2019}
\end{aligned}
$$

Eq. 8

Taking into account the value of the biophenols, the difference between PN and the other three cases decreased due to the higher price for PN (Figures 11 versus 10). ${ }^{34}$ Note that the price of products depends on various factors - such as scale of production, location of manufacturing — and consequently the ES should only be used for comparison purposes restricted to products with similar nature. 

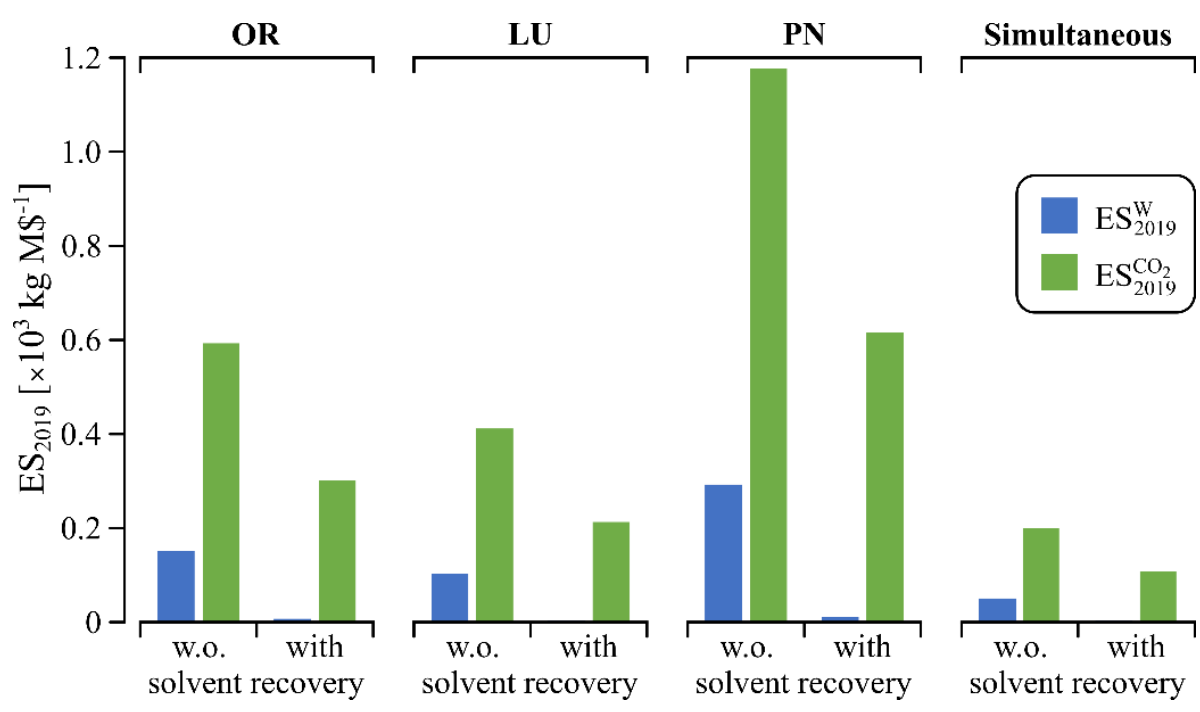

Figure 11. Economic sustainability for waste (left columns) and emitted $\mathrm{CO}_{2}$ (right columns) estimations for single biophenol isolation without (left clusters) and with (right clusters) in line solvent recycle, and for the simultaneous isolation process. Refer to Table S7-18 in the Supporting Information for the breakdown of calculations.

\section{Conclusions}

Imprinted materials were used for the continuous and simultaneous isolation of three biophenols from olive leaf waste via temperature-swing adsorption. In line solvent recycle was realized through organic solvent nanofiltration, which enabled both the waste and biophenol streams to be concentrated, while more than $97 \%$ of the extraction solvent was saved. The biophenol-specific imprinted polymers enabled the selective scavenging of the target compounds with $95-99 \%$ purity at a rate of $1.75,3.42$ and $0.12 \mathrm{~g}$ product per kg of scavenger per hour for OR, LU and PN, respectively.

Mathematical models for the adsorption dynamics and the membrane separation were developed to assist with the process optimization, reducing the need for excessive experimentation. The optimized process resulted in $61 \%$ and $49 \%$ reduction of the ecological and carbon footprints, respectively. Novel metrics for the assessment of economic sustainability for waste and emitted $\mathrm{CO}_{2}$ have been introduced.

The operation of the experimental setup was designed to be straightforward. The temperature-swing adsorption/desorption cycles are realized via diverting the flows with four, and six-way valves, without the need for change the settings of any of the pumps and thermostats. Due to the general and expandable nature of the model, the presented methodology opens new ways for modelling of fractionation of various valuable natural compounds and allows easy optimization of production of quasi-unlimited components. 


\section{Associated content}

\section{Supporting Information}

The Supporting Information is available free of charge on the ACS Publication website at DOI: 10.1021/acssuschemeng.9b04245

Chemical structures and compositions; biophenol characterization; adsorption column dynamics; adsorption isotherm expression; sensitivity analysis; effective intra-particular diffusivity estimation; calculation of the recovered and lost mass; membrane fabrication; membrane separations; green metrics calculations.

\section{Author information}

\section{Corresponding author}

*E-mail: $\quad$ claudi.fonte@manchester.ac.uk, $\quad$ gyorgy.szekely@ manchester.ac.uk, gyorgy.szekely@kaust.edu.sa; www.szekelygroup.com

\section{ORCID}

Virag Voros: 0000-0003-2208-5212

Enrico Drioli: 0000-0003-1092-5368

Claudio P. Fonte: 0000-0001-9714-0779

Gyorgy Szekely: 0000-0001-9658-2452

\section{Notes}

The authors declare no competing financial interest.

\section{Acknowledgement}

Useful discussions provided by Levente Cseri from The University of Manchester are greatly acknowledged. Preliminary experiments by Dr Christos Didaskalou from The University of Manchester are greatly acknowledged. TOC illustration and Front Cover were produced by Xavier Pita, scientific illustrator at King Abdullah University of Science and Technology (KAUST). This work was supported by the Royal Academy of Engineering's Newton Research Collaboration Programme [NRCP1516/1/41]. 


\section{References}

(1) Edenhofer, O.; Pichs-Madruga, R.; Sokona, Y.; Farahani, E.; Kadner, S.; Seyboth, K.; Adler, A.; Baum, I.; Brunner S.; Eickemeier, P. Contribution of Working Group III to the Fifth Assessment Report of the Intergovernmental Panel on Climate Change. 2014, 511-597.

(2) Henderson, R. K.; Jiménez-González, C.; Constable, D. J.; Alston, S. R.; Inglis, G. G.; Fisher, G.; Sherwood, J.; Binks, S. P.; Curzons, A. D. Expanding GSK's solvent selection guide - embedding sustainability into solvent selection starting at medicinal chemistry. Green Chem. 2011, 13, 854-862. https://doi.org/10.1039/C0GC00918K

(3) Alder, C. M.; Hayler, J. D.; Henderson, R. K.; Redman, A. M.; Shukla, L.; Shuster, L. E.; Sneddon, H. F. Updating and further expanding GSK's solvent sustainability guide. Green Chem. 2016, 18, 3879-3890. https://doi.org/10.1039/C6GC00611F

(4) OECD Environmental Outlook for the Chemical Industry. 2001, Paris, France. https://www.oecd.org/env/ehs/2375538.pdf (accessed 25 February 2019).

(5) Kefalas, P. Isolation of oleuropein from the leaves of olive tree. EP 1795201A1. 2007.

(6) Santos, J. H. P. M.; Almeida, M. R.; Martins, C. I. R.; Dias, A. C. R. V.; Freire, M. G.; Coutinho, J. A. P.; Ventura, S. P. M. Separation of phenolic compounds by centrifugal partition chromatography. Green Chem. 2018, 20, 1906-1916. https://doi.org/10.1039/C8GC00179K

(7) Japón-Luján, R.; Luque de Castro, M. L. Superheated liquid extraction of oleuropein and related biophenols from olive leaves. J. Chromatogr. A. 2006, 1136, 185-191. https://doi.org/10.1016/j.chroma.2006.09.081

(8) Mkaouara, S.; Gelicus, A.; Bahloul, N.; Allaf, K.; Kechaou, N. Kinetic study of polyphenols extraction from olive (Olea europaea L.) leaves using instant controlled pressure drop texturing. Sep. Purif. Technol. 2016, 161, 165-171. https://doi.org/10.1016/j.seppur.2016.02.002

(9) Xie, P.; Huang, L.; Zhang, C.; You, F.; Wang, C.; Zhou, H. Reduced-Pressure Boiling Extraction of Oleuropein Coupled with Ultrasonication from Olive Leaves (Olea europaea L.). Adv. Mater. Sci. Eng. 2015, 719485. http://dx.doi.org/10.1155/2015/719485

(10) Japón-Luján, R.; Luque-Rodríguez, J.; De Castro, M. L. Dynamic ultrasound-assisted extraction of oleuropein and related biophenols from olive leaves. J. Chromatogr. A. 2006, 1108, 76-82. https://doi.org/10.1016/j.chroma.2005.12.106

(11) Japón-Luján, R.; Luque-Rodríguez, J.; De Castro, M. L. Multivariate optimisation of the microwave-assisted extraction of oleuropein and related biophenols from olive leaves. Anal. Bioanal. Chem. 2006, 385, 753-759. https://doi.org/10.1007/s00216-006-0419-0 
(12) Conidi, C.; Drioli, E.; Cassano, A. Membrane-based agro-food production processes for polyphenol separation, purification and concentration. Curr. Opin. Food Sci. 2018, 23, 149164. https://doi.org/10.1016/j.cofs.2017.10.009

(13) Sholl, D. S.; Lively, R. P. Seven chemical separations to change the world. Nature 2016, 532, 435-437. https://doi.org/10.1038/532435a

(14) Drioli, E.; Stankiewicz, A. I.; Macedonio, F. Membrane engineering in process intensification - An overview. J. Membr. Sci. 2011, 380, 1-8. https://doi.org/10.1016/j.memsci.2011.06.043

(15) Koenig, S. G.; Sneddon, H. F. Recent advances in flow chemistry in the pharmaceutical industry. Green Chem. 2017, 19, 1418-1419. https://doi.org/10.1039/C7GC90017A

(16) Burcham, C. L.; Florence, A. J.; Johnson, M. D. Continuous Manufacturing in Pharmaceutical Process Development and Manufacturing. Annu Rev Chem Biomol Eng. 2018, 9, 253-281. https://doi.org/10.1146/annurev-chembioeng-060817-084355

(17) Szekely, G.; Jimenez-Solomon, M. F.; Marchetti, P.; Kim, J. F.; Livingston, A. G. Sustainability assessment of organic solvent nanofiltration: from fabrication to application. Green Chem. 2017, 16, 4440-4473. https://doi.org/10.1039/C4GC00701H

(18) Kim, J. F.; Szekely, G.; Schaepertoens, M.; Valtcheva, I. B.; Jimenez-Solomon, M. F.; Livingston, A. G. In Situ Solvent Recovery by Organic Solvent Nanofiltration. ACS Sustainable Chem. Eng. 2014, 2, 2371-2379. https://doi.org/10.1021/sc5004083

(19) Schaepertoens M., Didaskalou, C.; Kim, J. F.; Livingston, A. G.; Szekely, G. Solvent recycle with imperfect membranes: A semi-continuous workaround for diafiltration. J. Membr. Sci. 2016, 514, 646-658. https://doi.org/10.1016/j.memsci.2016.04.056

(20) Fodi, T.; Didaskalou, C.; Kupai, J.; Balogh, G. T.; Huszthy, P.; Szekely, G. NanofiltrationEnabled In Situ Solvent and Reagent Recycle for Sustainable Continuous-Flow Synthesis. ChemSusChem 2017, 10, 3435-3444. https://doi.org/10.1002/cssc.201701120

(21) Didaskalou, C.; Buyuktiryaki, S.; Kecili, R.; Fonte, C. P.; Szekely, G. Valorisation of agricultural waste with an adsorption/nanofiltration hybrid process: from materials to sustainable process design. Green Chem. 2017, 19, 3116-3125. https://doi.org/10.1039/C7GC00912G

(22) Sultan, Z.; Graça, I.; Li, Y.; Lima, S.; Peeva, L. G.; Kim, D.; Ebrahim, M. A.; Rinaldi, R.; Livingston, A. G. Membrane Fractionation of Liquors from Lignin-First Biorefining. ChemSusChem 2019, 12, 1203-1212. https://doi.org/10.1002/cssc.201802747 
(23) Tsibranska, H.; Peev, G. A.; Tylkowski, B. Fractionation of Biologically Active Compounds Extracted from Propolis by Nanofiltration. J Membr. Sci. Technol. 2011, 1, 100109. https://doi.org/10.4172/2155-9589.1000109

(24) Tylkowski, B.; Nowak, M.; Tsibranska, I.; Trojanowska, A.; Marciniak, L.; Valls, R. G.; Gumi, T.; Giamberini, M.; Jastrząb, R. Concentration and Fractionation of Polyphenols by Membrane Operations. Curr Pharm Des. 2017, 23, 231-241. https://doi.org/10.2174/1381612822666161021124358

(25) Xynos, N.; Papaefstathiou, G.; Psychis, M.; Argyropoulou, A.; Aligiannis, N.; Skaltsounis, A. L. Development of a green extraction procedure with super/subcritical fluids to produce extracts enriched in oleuropein. J. Supercrit. Fluids. 2012, 67, 89-93. https://doi.org/10.1016/j.supflu.2012.03.014

(26) Sahin, S.; Bilgin, M. Study on Oleuropein Extraction from Olive Tree (Olea europaea) Leaves by means of SFE: Comparison of Water and Ethanol as Co-Solvent. Sep. Sci. Technol. 2012, 47, 2391-2398. https://doi.org/10.1080/01496395.2012.666311

(27) Cifá, D.; Skrt, M.; Pittia, P.; Di Mattia, C.; Ulrih, N. P. Enhanced yield of oleuropein from olive leaves using ultrasound-assisted extraction. Food Sci. Nutr. 2018, 6, 1128-1137. https://doi.org/10.1002/fsn3.654

(28) Kupai, J.; Razali, M.; Buyuktiryaki, S.; Kecili, R.; Szekely, G. Long-term stability and reusability of molecularly imprinted polymers. Polym. Chem. 2017, 8, 666-673. https://doi.org/10.1039/C6PY01853J

(29) Razali, M.; Kim, J. F.; Attfield, M.; Budd, P. M.; Drioli, E.; Lee, Y. M.; Szekely, G. Sustainable wastewater treatment and recycling in membrane manufacturing. Green Chem. 2015, 17, 5196-5205. https://doi.org/10.1039/C5GC01937K

(30) Akretche, H.; Pierre, G.; Moussaoui, R.; Michaud, P.; Delattre, C. Valorization of olive mill wastewater for the development of biobased polymer films with antioxidant properties using eco-friendly processes. Green Chem. 2019, 21, 3065-3073. https://doi.org/10.1039/C9GC00828D

(31) Cavaca, L. A. S.; Rodrigues, C. A. B.; Simeonov, S. P.; Gomes, R. F. A.; Coelho, J. A. S.; Romanelli, G. P.; Sathicq, A. G.; Martínez, J. J.; Afonso, C. A. M. Valorization of Oleuropein via Tunable Acid-Promoted Methanolysis. ChemSusChem 2018, 11, 2300-2305. https://doi.org/10.1002/cssc.201800980

(32) Göransson, U.; Gunasekera, S.; Malik, S.; Park, S.; Slazak, B.; Jacobsson, E.; Eriksson, C.; Andersson, H.; Strömstedt, A. Peptide biodiscovery from plants and animals: structure to function. Planta Med. 2016, 82, S1-S381. https://doi.org/10.1055/s-0036-1596156 
(33) Slater, C. S.; Savelski, M. J.; CarSole, W. A.; Constable, D. J. C. Green Chemistry in the Pharmaceutical Industry. in ed. Dunn, P. J.; Wells, A. S.; Williams, M. T. Wiley-VCH Verlag GmBH \& Co. 2010, 3, 49-82.

(34) Sigma-Aldrich Corporation, price for oleuropein: $\$ 12.2 \mathrm{k}$, luteolin: $\$ 12.9 \mathrm{k}$, pinoresinol: $\$ 23.4 \mathrm{k} \mathrm{g}^{-1}$ having $\geq 98.0 \%$ purity (accessed 26 February 2019 )

\section{Table of Contents Graphic}

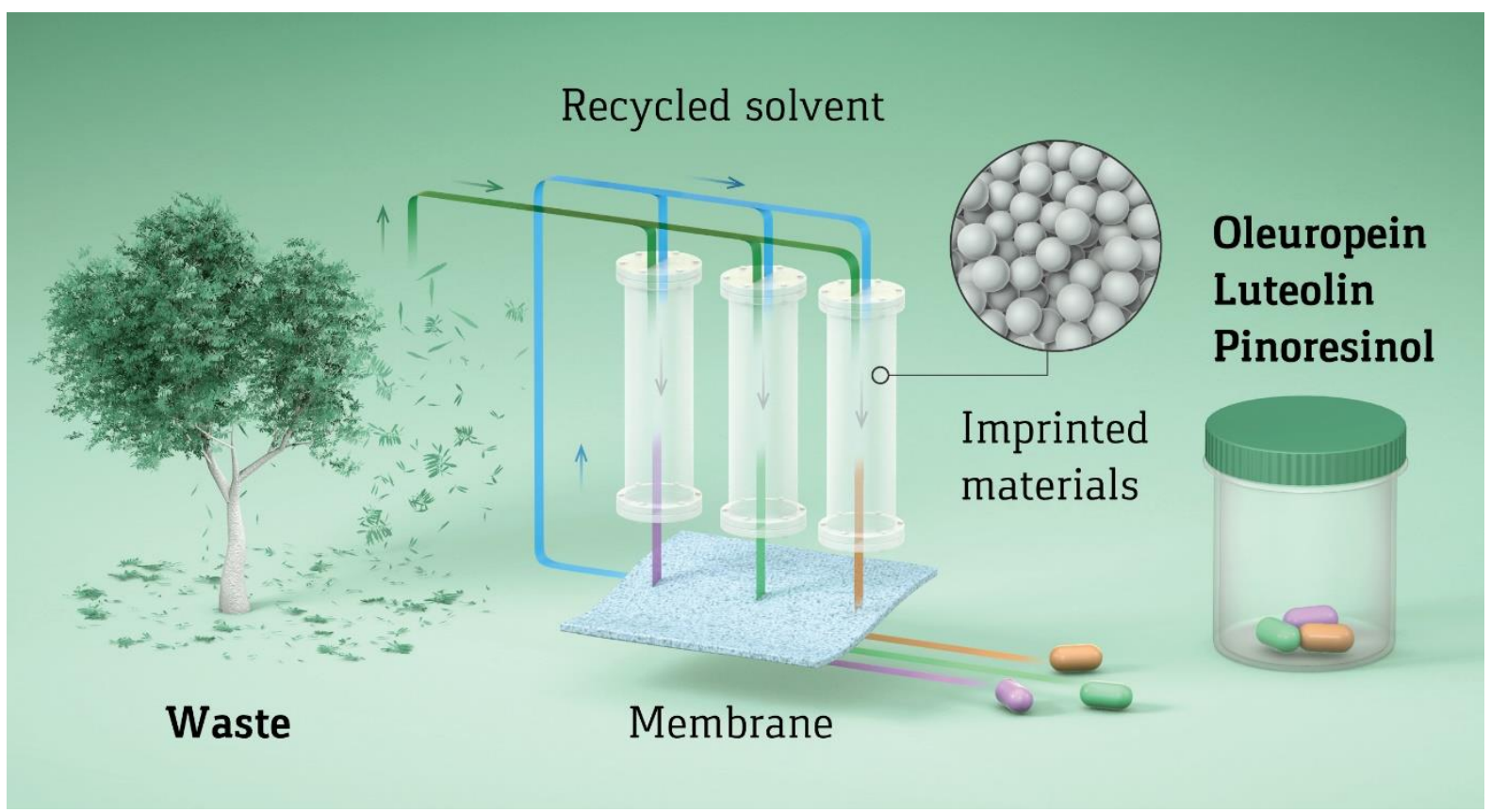

Three biophenols, with pharmaceutical grade, were simultaneously isolated from agricultural waste. In line solvent recycle was realized through product and waste concentration using nanofiltration. $E$ factor, carbon footprint and economic sustainability were assessed. 